\title{
Endoscopic palliative treatment versus surgical bypass in malignant low bile duct obstruction: A systematic review and meta-analysis
}

\author{
Silvia Lucia Alves de Lima, Fabio Alberto Castillo Bustamante, \\ Eduardo Guimarães Hourneaux de Moura, Wanderley Marques \\ Bernardo, Everson Luiz de Almeida Artifon, Dalton Marques Chaves, \\ Tomazo Antonio Prince Franzini, Carlos Kiyoshi Furuya Junior
}

\section{ABSTRACT}

Aims: Despite technological advances, only about $20 \%$ of periampullary tumors are found to be resectable at the time of presentation. Biliary tree obstruction and consequent jaundice occur in $70-90 \%$ of those patients and has important consequences for a patient's quality of life. Relief of biliary tree obstruction is the main goal for treatment, and few options for palliative therapy of biliary tree obstruction can be performed, including surgical bypass, percutaneous stenting, and endoscopic stenting. Objective: The aim of the present study was to acquire and analyze data to compare the success of procedures, procedure-related complication, mortality in 30

Silvia Lucia Alves de Lima1, Fabio Alberto Castillo Bustamante ${ }^{1}$, Eduardo Guimarães Hourneaux de Moura ${ }^{2}$, Wanderley Marques Bernardo ${ }^{3}$, Everson Luiz de Almeida Artifon ${ }^{1}$, Dalton Marques Chaves ${ }^{1}$, Tomazo Antonio Prince Franzini $^{1}$, Carlos Kiyoshi Furuya Junior ${ }^{1}$

Affiliations: ${ }^{1} \mathrm{MD}$ Gastrointestinal Endoscopy Unit, Hospital das Clinicas, University of Sao Paulo Medical School. São Paulo, São Paulo, Brazil; ' ${ }^{2}$ Head Teacher Gastrointestinal Endoscopy Unit, Hospital das Clinicas, University of Sao Paulo Medical School. São Paulo, São Paulo, Brazil; ${ }^{3}$ Methodological Adviser Gastrointestinal Endoscopy Unit, Hospital das Clinicas, University of Sao Paulo Medical School. São Paulo, São Paulo, Brazil.

Corresponding Author: Fabio Alberto Castillo Bustamante, MD, Gastrointestinal Endoscopy Unit, Hospital das Clinicas, University of Sao Paulo Medical School. São Paulo, São Paulo, Brazil, Adress Av DrEnéas de carvalhoAguiar 255 andarbloco 03, Postal Code 05403900; Ph: 1126616221, Fax: 1126616463; Email: facastillobu@gmail.com

Received: 27 March 2015

Accepted: 14 May 2015

Published: 13 June 2015 days, recurrent-jaundice rates in endoscopic, and surgical palliative techniques. Methods: Two independent reviewers searched the following electronic databases: Medline, EMBASE, Cochrane, LILACS, BVS, SCOPE, and CINAHL (EBSCO). Inclusion criteria included studies involving patients with distal biliary obstruction due to periampullary tumors who underwent endoscopic therapy or a surgical procedure for palliation. Results: No differences were observed for success of procedures; differences were observed with better outcomes for endoscopy therapy with regards to mortality associated with procedure, complication associated with procedure, and mortality in 30 days. Also, differences were observed with better outcomes for surgery therapy for recurrent-jaundice. Conclusion: Endoscopic palliative drainage is associated with a lower rate in complication, mortality associated with procedure, and mortality in 30 days. Recurrent-jaundice analysis demonstrated an overall lower rate in surgical bypass procedures. No differences were found for the success of procedures.

Keywords: Periampullary tumors, Bile duct cancer, Cholangiocarcinoma, Pancreatic carcinoma, Endoscopy, Gastrointestinal, Surgical procedures

\section{How to cite this article}

Alves de Lima SL, Bustamante FAC, Hourneaux de Moura EG, Bernardo WM, Artifon ELA, Chaves DM, Franzini TAP, Junior CKF. Endoscopic palliative treatment versus surgical bypass in malignant low bile duct obstruction: A systematic review and metaanalysi. Int J Hepatobiliary Pancreat Dis 2015;5:3546. 
Article ID: 100032IJHPDSL2015

$* * * * * * * * *$

doi:10.5348/ijhpd-2015-32-CR-7

\section{INTRODUCTION}

Jaundice due to biliary obstruction is usually the main symptom at the time of diagnostic in periampullary cancers. Despite technological advances, only about $20 \%$ of periampullary tumors are found to be resectable at the time of presentation. Biliary tree obstruction and consequent jaundice occur in $70-90 \%$ of those patients and has important consequences for a patient's quality of life. Palliation remains the principal management in such patients because of this dismal natural history, and relief of biliary tree obstruction is a prime concern $[1,2]$.

Few options for palliative therapy of biliary tree obstruction can be performed, including surgical bypass, percutaneous stenting, and endoscopic stenting. Although initial results with surgical bypass demonstrated low rates of recurrent jaundice $(2-5 \%)$, the surgery itself carries an appreciable risk of post-operative morbidity and mortality, up to $24 \%$ in some trials [3, 4]. Surgical decompression has been advocated in patients who at the time of laparotomy for planned tumor resection are found to have unresectable disease as well as in occasional patients with longer projected survival $[5,6]$. Advances in minimally invasive therapy have led to the development of luminal stents whose insertion can relieve jaundice and hence avoid the need for surgery [7-9].

Early biliary stents came in the form of a plastic prosthesis that was inserted across the obstructing mass to provide drainage of the biliary tree; however, bilioduodenal reflux and food fibers result in stent blockage. Various changes in plastic stent design and adjunctive therapy such as antibiotics have failed to significantly improve their patency [10]. With a wider bore than plastic stents, several studies have shown that they exhibit superior patency to plastic stents [11-13].

Obstructive jaundice due to malignant distal biliary obstruction can thus be relieved by surgery or endoscopic metal or plastic stents $[14,15]$. A number of randomized controlled trials (RCTs) have compared various combinations of these interventions [16, 17]. Endoscopic stents appear to offer a less invasive option, but the many designs and stent types available have made selecting the ideal stent for individual patients complicated. This paper reviews the outcomes associated with surgery and endoscopic therapies.

\section{OBJECTIVES}

The aim of the present study is to acquire and analyze data to compare success of procedure, procedure-related complication, mortality in 30 days, and recurrent-jaundice rates in endoscopic surgical procedures in patients with distal biliary obstruction due to periampullary tumors (i.e., pancreatic neoplasms or low bile duct carcinoma).

\section{MATERIALS AND METHODS}

\author{
Protocol and Registration \\ PROSPERO 2015 CRD42015017792 [18] \\ Guidelines http://www.prisma-statement.org/ \\ statement.htm
}

\section{Eligibility Criteria}

a) Types of studies: Randomized clinical trials, controlled clinical trial, and cohort studies.

b) Types of participants: Patients with distal biliary obstruction due to periampullary tumors (i.e., pancreatic neoplasms or low bile duct carcinoma).

c) Types of intervention: Comparison between endoscopic palliative stents and surgical palliative procedures.

d) Types of outcome measures: The main outcome measures were the following: success of procedure, procedure-related complication, mortality in 30 days, and recurrent-jaundice rates.

In this literature search, we do not limit ourselves by year of publication or by language.

Information sources include MEDLINE as well as the Cochrane Controlled Trials Register, EMBASE, EBSCO, LILACS, Library University of Sao Paulo, Research website BVS, and SCOPE.

\section{Search}

\section{Medline:}

P: "(Periampullary Tumors OR Biliary Tract Neoplasms OR Biliary Tract Cancer OR Biliary tract tumors OR Bile Duct Cancer OR Pancreatic Neoplasms OR Cholangiocarcinoma OR Pancreatic Carcinoma) AND

I: (Endoscopy OR Endoscopy, Gastrointestinal) AND

C: (Surgery OR Surgical Procedures, Operative)".

\section{Embase:}

P: Pancreatic neoplasms OR bile duct neoplasms AND

I: endoscopy AND

C: surgery AND

('clinical trial' OR 'controlled study' OR 'major clinical study' OR 'prospective study' OR 'retrospective study'))". Cochrane, LILACS, Scopus and CINAHL:

P: pancreatic neoplasms OR bile duct neoplasms AND

I: endoscopy AND

C: surgery 


\section{Study Selection}

Eligibility assessment was performed independently in an unblinded, standardized manner by two reviewers. Assessment included a thorough reading of the abstract to identify studies that compare endoscopic with surgical techniques. Studies selected were read in their entirety and excluded according criteria JADAD [19], NEWCASTLE OTTAWA [20] and Methodology Check List SIGN [21]. Studies that did not report the results in absolute numbers and those not written in English, Spanish, or Portuguese were excluded. Disagreements between reviewers were resolved by consensus.

\section{Data Collection Process and Items}

We extracted data by a detailed reading of the results of each study. This included information on the success of the procedure, procedure-related complication, mortality in 30 days, and recurrent-jaundice rates. We only included absolute numbers reported in the text of the article or with the analysis of graphs. We excluded an article for not reporting the results in absolute numbers. One review author extracted the following data from included studies, and the second author checked the extracted data. Disagreements were resolved by discussion between the two reviewers; we did not contact authors for further information.

\section{Data items}

The following information was extracted from each included study: Characteristics of population (type and location of tumors); type of intervention, considering different modalities of techniques in endoscopic treatment (plastic stents, metallic stents, covered or uncovered stents) versus surgical approach (hepaticojejunostomy, cholecystojejunostomy, choledocojejunostomy and gastrojejunostomy associated); type of outcome measure including complications, success of procedure, morbidity, mortality, survival in 30 days, recurrent-jaundice, and hospitalization rates.

\section{Risk of Bias In Individual Studies}

Since both cohort and randomized studies were included, the risk of bias in individual studies was assessed using the Newcastle-Ottawa Quality Assessment for cohort studies [20] and JADAD Scale for randomized trials [19] as well as the Methodology Check List: SIGN for both [21, 22].

We extracted data into a table of all studies with the identification of all potential bias of each study. Then, different factors were identified as individual generators of biases, including age, comorbidities, techniques used, prevalence, and experience.

\section{Summary Measures}

Individual analysis for each study included the following: experiment events rate (EER), control event rate (CER), number needed to treat (NNT), and absolute risk (ARR).

\section{Synthesis of Results}

We performed a meta-analysis with the software RevMan5 [23] using the following characteristics: dichotomous data type, statistical method of MantelHaenszel, fixed effect model analysis, effect measure risk difference, study confidence interval 95\%, total confidence interval $95 \%$, and year of study.

\section{Risk of bias across studies.}

To identify true heterogeneity and cause for publication bias between studies, we conducted both a graphic funnel plot and a I2 analysis. We noted a value of I2 greater than $50 \%$ as having high heterogeneity. If the study was outside the funnel plot it was regarded as publication bias, but if it was inside the funnel plot it was considered as having true heterogeneity.

\section{RESULTS}

\section{Study Selection}

We identified 8238 studies through MEDLINE, We identified 1941 studies through COCHRANE, LILACS, SCOPUS, and CINAHL. Eliminating repeated studies, we found 9179 studies in total. We excluded studies that did not have information about periampullary cancers. We chose eight studies that we reviewed with JADAD [19], NEWCASTLE OTTAWA [20], and the methodology check list: Cohort and clinical trial studies SIGN [21]. We excluded a study that was written in French. We included seven studies for qualitative analysis and five studies for quantitative analysis (Figure 1).

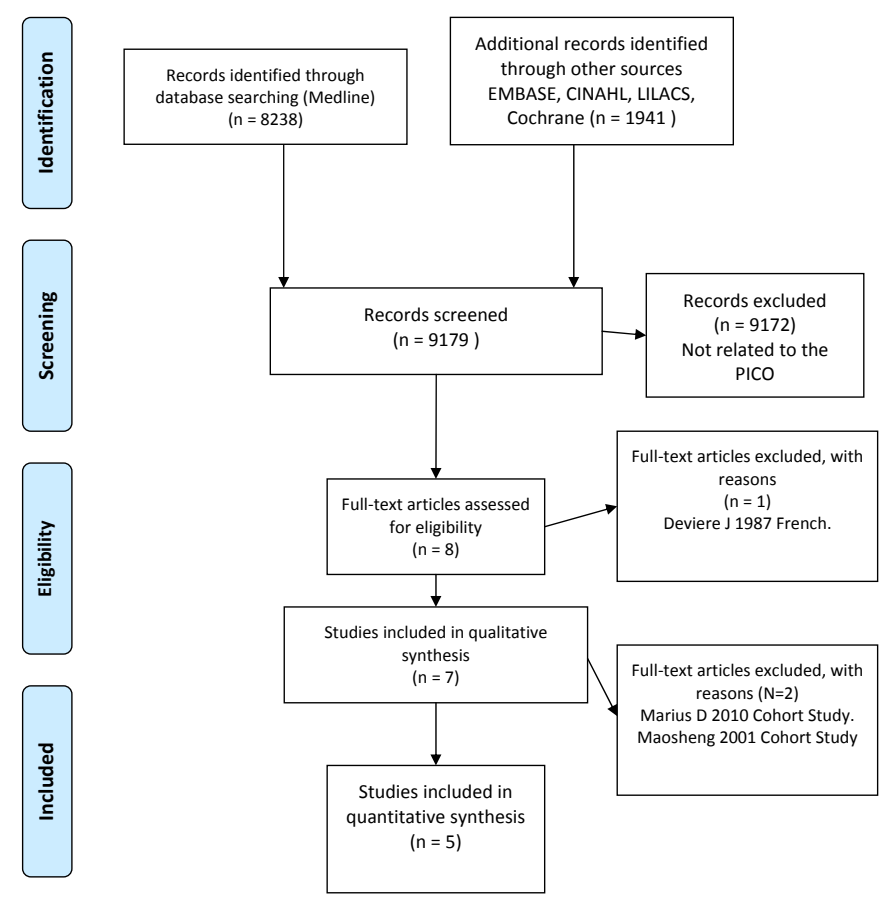

Figure 1: Flow Diagram. 


\section{Study Characteristics}

The characteristics of the studies are summarized in Table 1. Table 2 describes the oncologic diagnosis analyzed, the number of interventions for each treatment group, and the report in absolute numbers for each outcome of interest extracted. The survival and hospital stay was expressed in mean without standard error, was no topic under analysis [24-29].

\section{Risk of Bias Within Studies}

We identify biases selected for qualitative analysis studies and evaluate them according criteria from the JADAD, Methodology check list: SIGN, and NEWCASTLE OTTAWA [19-21] (Table 2).

\section{Summary Measures}

Individual analysis for each study included the following: experiment events rate (EER), control event rate (CER), number needed to treat (NNT), and absolute risk (ARR) (Table 3).

\section{Results of Individual Studies and Synthesis of}

\section{Results}

\section{Procedure Success}

Five clinical trial reported procedure success, and the heterogeneity test indicated a $\chi^{2}$ of 4.09 and a I2 of $2 \%$, demonstrating low heterogeneity. The fixed-effects model was adopted, and the RD was 0.02 (95\% CI: -0.04, 0.07) (Figure 2). Analysis of the pooled data revealed no statistically significant differences in procedure success between the two therapies.

\section{Mortality associated with procedure}

Mortality associated with procedure: two clinical trials reported mortality associated with procedure, and the heterogeneity test indicated a $\chi 2$ of 2.57 and a I2 of $61 \%$, demonstrating high heterogeneity. The fixed-effects model was adopted, and the risk difference was -0.10 (95 \% CI: -0.16, -0.03) (Figure 3a). Analysis of the pooled data revealed differences in mortality associated with procedure with significant risk of bias. The funnel plot analysis identified true heterogeneity, and by consensus of reviewers we opted to perform the meta-analysis using the risk ratio.

Table 1: Study Characteristics.

\begin{tabular}{|c|c|c|c|c|c|c|c|c|c|}
\hline STUDY & POPULATION & INTERVENTION & Succ & $\begin{array}{l}\text { Mor } \\
\text { proc }\end{array}$ & $\begin{array}{l}\text { Mor } \\
\text { 30d }\end{array}$ & Comp & Surv & $\begin{array}{c}\mathrm{Re}- \\
\text { jaund }\end{array}$ & $\begin{array}{l}\text { Hos- } \\
\text { stay }\end{array}$ \\
\hline \multirow{3}{*}{$\begin{array}{l}\text { Marius Distler } \\
2010 \text { Cohort } \\
\text { Study [24] }\end{array}$} & \multirow{3}{*}{$\begin{array}{c}\text { Obst Jaudance } \\
\text { Palliative ADPH-TB } \\
\text { N247 }\end{array}$} & P Stent N138 & & & 3 & 7 & $\begin{array}{l}5.1 \\
\text { mo }\end{array}$ & 0 & \\
\hline & & $\begin{array}{l}\text { P Stent + HJ } \\
\text { Bypass N68 }\end{array}$ & & & 0 & 12 & $\begin{array}{l}9.4 \\
\mathrm{mo}\end{array}$ & 0 & \\
\hline & & HJ Bypass N41 & & & 1 & 6 & $\begin{array}{l}6.3 \\
\text { mo }\end{array}$ & 3 & \\
\hline \multirow{2}{*}{$\begin{array}{c}\text { Artifon } 2006 \\
\text { Clinical Trial 01- } \\
04[8]\end{array}$} & \multirow{2}{*}{$\begin{array}{c}\text { Obst Jaudance } \\
\text { Palliative ADPH-TB } \\
\text { N30 }\end{array}$} & M Stent 15 & 15 & 0 & 0 & 6 & $\begin{array}{l}5,2 \\
\text { mo }\end{array}$ & 4 & 2 \\
\hline & & \begin{tabular}{|c|} 
HJ HCJ Bypass \\
15 \\
\end{tabular} & 15 & 0 & 0 & 9 & $\begin{array}{l}6,5 \\
\text { mo }\end{array}$ & 1 & 9 \\
\hline \multirow{2}{*}{$\begin{array}{l}\text { Maosheng } 2001 \\
\text { Cohort Study } \\
83-99 \text { [25] }\end{array}$} & \multirow{2}{*}{$\begin{array}{c}\text { Obst Jaudance } \\
\text { Palliative ADPH } \\
\text { N60 }\end{array}$} & $\begin{array}{c}\text { M (Cov Unc) } \\
\text { Stent } 19 \\
\end{array}$ & 18 & & 1 & 9 & $\begin{array}{l}6.6 \\
\mathrm{mo}\end{array}$ & 5 & 12 \\
\hline & & $\begin{array}{l}\text { HJ HCJ + or - } \\
\text { Bypass } 41 \\
\end{array}$ & 41 & & 0 & 13 & $\begin{array}{l}7.5 \\
\text { mo }\end{array}$ & 2 & 32 \\
\hline \multirow{2}{*}{$\begin{array}{c}\text { Smith } 1994 \\
\text { Clinical Trial } \\
\text { [26] }\end{array}$} & \multirow{2}{*}{$\begin{array}{c}\text { Obst Jaudance } \\
\text { Palliative ADPH-TB } \\
\text { N201 }\end{array}$} & P Stent N101 & 95 & 3 & 8 & 29 & $\begin{array}{l}5.2 \\
\mathrm{mo}\end{array}$ & 36 & 19 \\
\hline & & $\begin{array}{l}\text { HJ HCJ + or - } \\
\text { Bypass N100 }\end{array}$ & 94 & 14 & 15 & 58 & $\begin{array}{l}6.5 \\
\text { mo }\end{array}$ & 2 & 26 \\
\hline \multirow{2}{*}{$\begin{array}{c}\text { Andersen } 1989 \\
\text { Clinical Trial } \\
\text { [27] }\end{array}$} & \multirow{2}{*}{$\begin{array}{c}\text { Obst Jaudance } \\
\text { Palliative ADPH-TB } \\
\text { N50 }\end{array}$} & P Stent N25 & 24 & & 5 & 9 & $\begin{array}{l}2.7 \\
\mathrm{mo}\end{array}$ & 1 & 26 \\
\hline & & $\begin{array}{c}\text { HJ HCJ Bypass } \\
\text { N25 }\end{array}$ & 22 & & 6 & 5 & $\begin{array}{l}3.2 \\
\mathrm{mo}\end{array}$ & 3 & 27 \\
\hline \multirow{2}{*}{$\begin{array}{c}\text { Shepherd } 1988 \\
\text { Clinical Trial } \\
\text { [28] }\end{array}$} & \multirow{2}{*}{$\begin{array}{c}\text { Obst Jaudance } \\
\text { Palliative ADPH-TB } \\
\text { N52 }\end{array}$} & Stent N23 & 19 & & 3 & 7 & $\begin{array}{l}5.1 \\
\mathrm{mo}\end{array}$ & 7 & \\
\hline & & Bypass N25 & 23 & & 5 & 14 & $\begin{array}{l}4.2 \\
\mathrm{mo}\end{array}$ & 0 & \\
\hline \multirow{2}{*}{$\begin{array}{l}\text { Bornman } 1986 \\
\text { Clinical Trial } \\
\text { [29] }\end{array}$} & \multirow{2}{*}{$\begin{array}{c}\text { Obst Jaudance } \\
\text { Palliative ADPH } \\
\text { N53 }\end{array}$} & Stent N23 & 21 & & 2 & 7 & $\begin{array}{l}4.7 \\
\mathrm{mo}\end{array}$ & 8 & 18 \\
\hline & & Bypass N25 & 19 & & 5 & 8 & $\begin{array}{l}3.7 \\
\mathrm{mo}\end{array}$ & 3 & 24 \\
\hline & \multicolumn{2}{|c|}{$\begin{array}{r}\text { HJ Hepatojejunostomy } \\
\text { HCJ Hepatocholedocojejunostomy } \\
\text { ADPH Pancreatic adenocarcinoma head } \\
\text { TB Biliary Tree } \\
\text { Succ Success } \\
\text { Mor proc Mortality procedure }\end{array}$} & & & \multicolumn{5}{|c|}{$\begin{array}{r}\text { Mor 30d Mortality in } 30 \text { days } \\
\text { Comp complication } \\
\text { Surv survival } \\
\text { Re-jaund recurrent-jaundice } \\
\text { hstay hospital Stay } \\
\text { mo month }\end{array}$} \\
\hline
\end{tabular}


Table 2: Risk of blas within studies.

\begin{tabular}{|c|c|c|c|c|c|c|}
\hline WORK & POPULATION & INTERVENTION & Other bies & $\begin{array}{l}\text { NEW } \\
\text { CASTEL }\end{array}$ & JADAD & SIGN \\
\hline \multirow{3}{*}{$\begin{array}{l}\text { Marius Distler } \\
2010 \text { Cohort } \\
\text { Study [24] }\end{array}$} & \multirow{3}{*}{$\begin{array}{c}\text { Obst Jaudance } \\
\text { Palliative } \\
\text { ADPH-TB } \\
\text { N247 } \\
\end{array}$} & P Stent N138 & $63 y$ 2,2 mean enchange & \multirow{3}{*}{ 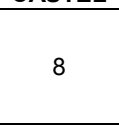 } & & \multirow{3}{*}{ accept } \\
\hline & & $\begin{array}{l}\text { P Stent + HJ } \\
\text { Bypass N68 }\end{array}$ & $63 y$ & & & \\
\hline & & HJ Bypass N41 & $63 y$ & & & \\
\hline \multirow{2}{*}{$\begin{array}{l}\text { Artifon } 2006 \\
\text { Clinical Trial } \\
01-04[8]\end{array}$} & \multirow{2}{*}{$\begin{array}{l}\text { Obst Jaudance } \\
\text { Palliative } \\
\text { ADPH-TB N30 }\end{array}$} & M Stent 15 & $\begin{array}{c}64.2 y, \text { succes reduction } \\
50 \% \text { B }\end{array}$ & & \multirow{2}{*}{3} & \multirow{2}{*}{ accept } \\
\hline & & $\begin{array}{l}\text { HJ HCJ Bypass } \\
15\end{array}$ & 61.4y Dont lost & & & \\
\hline \multirow{2}{*}{$\begin{array}{c}\text { Maosheng } \\
\text { 2001 Cohort } \\
\text { Study 83-99 } \\
\text { [25] }\end{array}$} & \multirow[t]{2}{*}{$\begin{array}{l}\text { Obst Jaudance } \\
\text { Palliative } \\
\text { ADPH N60 }\end{array}$} & M Stent 19 & $\begin{array}{c}67.5 \mathrm{y}, \mathrm{MS} 8-10 \mathrm{~mm} \text { 6- } \\
8 \mathrm{~cm}, \mathrm{~B} 13.7(1.2), \\
\text { success redution B } 2 \\
\text { week } 16 \text { preprocedure } \\
\text { drainage } 8 \text { P Stent Hstay } \\
12 \\
\end{array}$ & \multirow[t]{2}{*}{8} & & \multirow[t]{2}{*}{ accept } \\
\hline & & $\begin{array}{l}\text { HJ HCJ CJ + or - } \\
\text { Bypass } 41\end{array}$ & $\begin{array}{c}66.0 y, \text { B8.8 (1), success } \\
\text { redution B } 2 \text { week } 34 \\
\text { preoperative drainage } 3 \text { P } \\
\text { Stent Hstay } 32 . \\
\end{array}$ & & & \\
\hline \multirow[t]{2}{*}{$\begin{array}{l}\text { Smith } 1994 \\
\text { Clinical Trial } \\
{[26]}\end{array}$} & \multirow[t]{2}{*}{$\begin{array}{l}\text { Obst Jaudance } \\
\text { Palliative } \\
\text { ADPH-TB-AM- } \\
\text { VA N201 }\end{array}$} & P Stent N101 & $\begin{array}{c}\text { 70y B270; TS 3; } \\
\text { Percutaneos if CPRE fail, } \\
\text { PS10FR, Intention to } \\
\text { treat success redution } \\
20 \% \text { B } 5 \text { day, } 19 \\
\text { RENDESVOUZ, } 4.5 \mathrm{~m} \\
\text { mean enchange } \\
\end{array}$ & & 3 & \multirow[t]{2}{*}{ accept } \\
\hline & & $\begin{array}{l}\text { HJ HCJ + or - } \\
\text { Bypass N100 }\end{array}$ & $\begin{array}{c}\text { 70y B 311, TS 3.6, } \\
\text { intention to treat, success } \\
\text { redution } 20 \% \text { B } 5 \text { day } \\
\text { LOST } 3 \%\end{array}$ & & & \\
\hline \multirow{2}{*}{$\begin{array}{l}\text { Andersen } \\
1989 \text { Clinical } \\
\text { Trial [27] }\end{array}$} & \multirow{2}{*}{$\begin{array}{l}\text { Obst Jaudance } \\
\text { Palliative } \\
\text { ADPH-TB N50 }\end{array}$} & P Stent N25 & $\begin{array}{l}77 y, \text { succes reduction } \\
50 \% \text { B, 7-10Fr OS, }\end{array}$ & & \multirow[b]{2}{*}{3} & \multirow[b]{2}{*}{ accept } \\
\hline & & $\begin{array}{l}\text { HJ HCJ CD } \\
\text { Bypass N25 }\end{array}$ & $\begin{array}{c}76 y, 19 \text { treated according } \\
\text { to randomisation, } 10 \% \\
\text { lost. }\end{array}$ & & & \\
\hline \multirow{2}{*}{$\begin{array}{c}\text { Shepherd } \\
1988 \text { Clinical } \\
\text { Trial [28] } \\
\end{array}$} & \multirow{2}{*}{\begin{tabular}{|l|} 
Obst Jaudance \\
Palliative \\
ADPH-TB N52 \\
\end{tabular}} & Stent N23 & LOST $10 \%$ & & \multirow[b]{2}{*}{3} & \multirow[b]{2}{*}{ accept } \\
\hline & & Bypass N25 & & & & \\
\hline \multirow{2}{*}{$\begin{array}{c}\text { Bornman } 1986 \\
\text { Clinical Trial } \\
{[29]} \\
\end{array}$} & \multirow{2}{*}{$\begin{array}{l}\text { Obst Jaudance } \\
\text { Palliative } \\
\text { ADPH N53 }\end{array}$} & Stent N25 & $\begin{array}{l}61 \mathrm{y} \text { treated according to } \\
\text { randomisation, } 10 \% \text { lost. }\end{array}$ & & \multirow[t]{2}{*}{3} & \multirow[t]{2}{*}{ accept } \\
\hline & & Bypass N25 & $61 y$ & & & \\
\hline \multicolumn{3}{|c|}{$\begin{array}{r}\text { HJ Hepatojejunostomy } \\
\text { HCJ Hepatocholedocojejunostomy }\end{array}$} & \multicolumn{4}{|c|}{$\begin{array}{r}\text { ADPH Pancreatic adenocarcinoma head } \\
\text { TB Biliary Tree }\end{array}$} \\
\hline
\end{tabular}

Table 3: Summary Measures

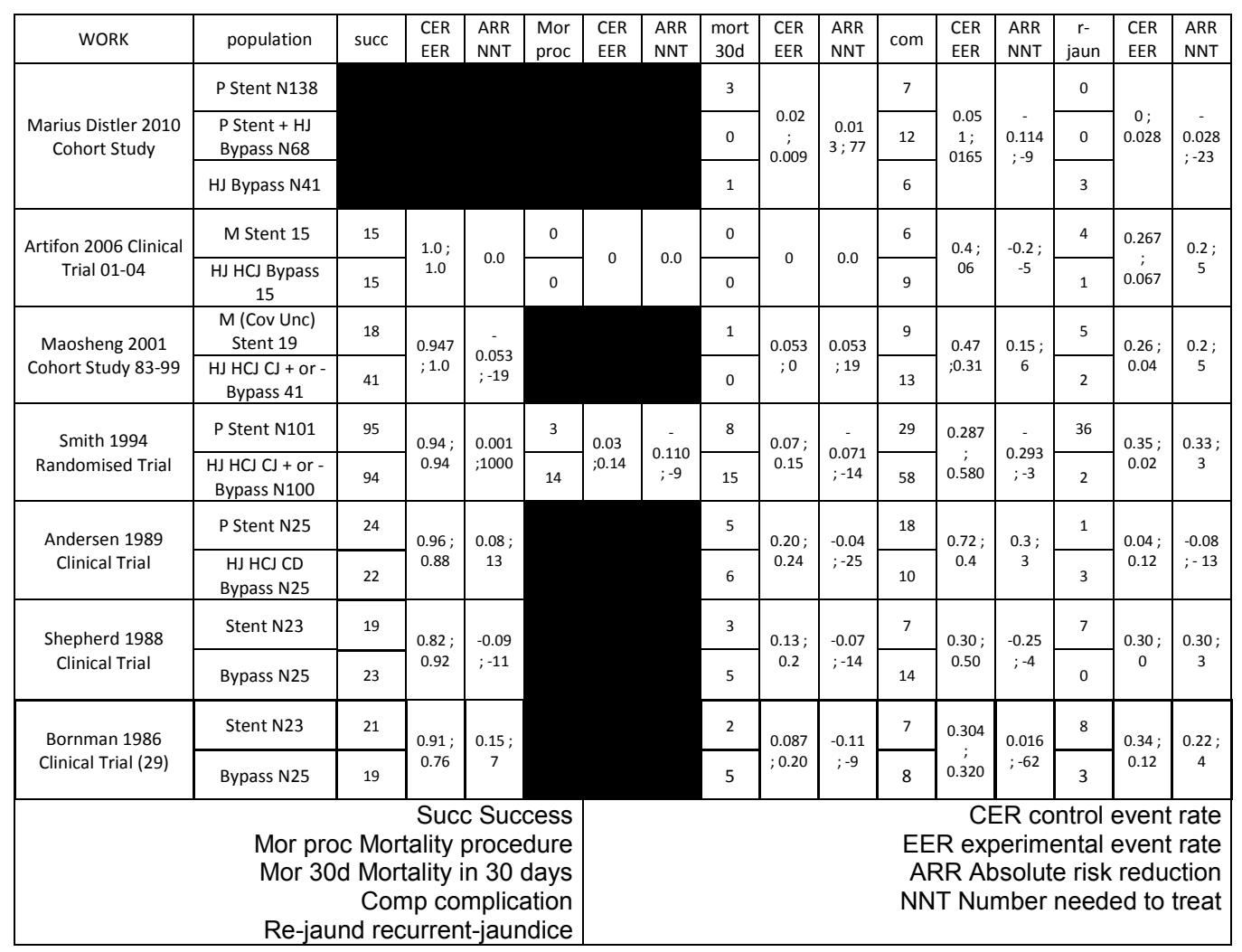


Mortality associated with procedure: two clinical trials reported mortality associated with procedure; the heterogeneity test was not applicable. The fixed-effects model was adopted, and the risk ratio was 0.21 (95\% CI: -0.16, -0.03) (Figure 3b). Analysis of the pooled data revealed differences in mortality associated with procedure that favored endoscopy therapy, with potential bias in this statement.

\section{Mortality 30 Days}

Mortality at 30 days: Five clinical trials reported mortality at 30 days; the heterogeneity test indicated a $\chi^{2}$ of 1.44 and a I2 of $0 \%$, demonstrating homogeneity. The fixed-effects model was adopted, and the RD was -0.07 (95 \% CI: -0.13, 0.00) (Figure 4). Analysis of the pooled data revealed statistically significant differences in mortality at 30 days between the two therapies and favors endoscopy therapy.

\section{Complication associated with procedure}

Complication associated with procedure: five clinical trials reported complication associated with procedure; the heterogeneity test indicated a $\chi^{2}$ of 12.10 and a I2 of $67 \%$, demonstrating high heterogeneity. The fixedeffects model was adopted, and the RD was -0.19 (95\% CI: -0.28, -0.09) (Figure 5a). Analysis of the pooled data revealed differences mortality associated with procedure, with potential bias in this statement. In the funnel plot analysis, the study Andersen (1999) was identified as a source of heterogeneity for publication bias. By consensus of reviewers, we opted to withdraw this work from the meta-analysis complication associated with procedure (Figure 5b).

Complication associated with procedure for endoscopy and surgery therapies: four studies reported complication associated with procedure; the heterogeneity test indicated a $\chi^{2}$ of 3.50 and an I2 of $14 \%$, demonstrating low heterogeneity. The fixed-effects model was adopted, and the RD was -0.24 (95\% CI: -0.34, -0.24) (Figure 5 b). Analysis of the pooled data revealed statistically significant differences in complication associated with procedure and showed better outcomes for endoscopy therapy.

\section{Recurrent-Jaundice}

Recurrent-Jaundice: five clinical trials reported Recurrent-Jaundice; the heterogeneity test indicated a $\chi^{2}$ of 22.53 and an I2 of $87 \%$, demonstrating high heterogeneity. The fixed-effects model was adopted, and the RD was 0.25 (95\% CI: 0.18, 0.32) (Figure 6a). Analysis of the pooled data revealed differences for Recurrent-Jaundice with significant risk of bias in does this affirmation. In the funnel plot analysis, the study Andersen (1989) was identified as a source of heterogeneity for publication bias. By consensus of

\section{Procedure Success}

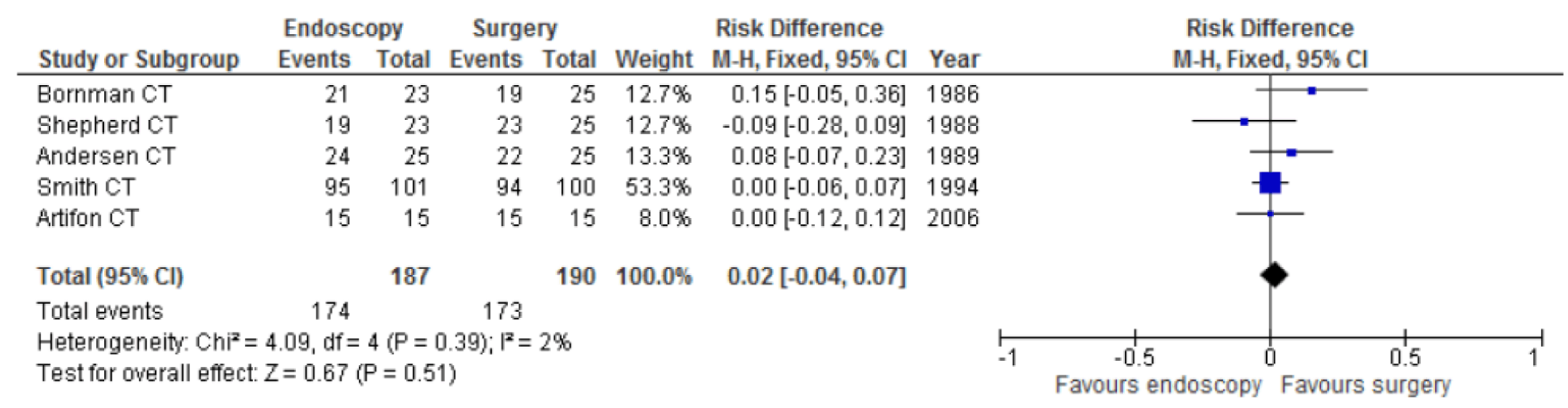

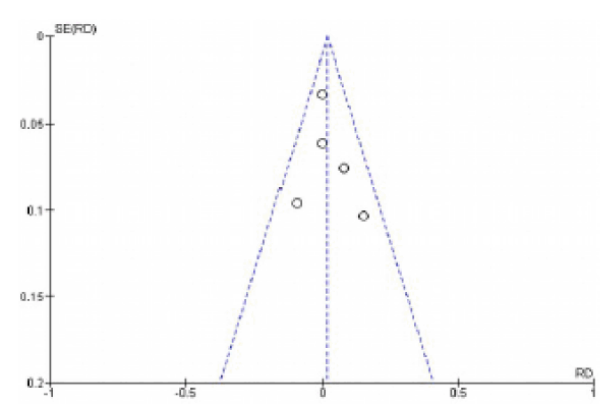

Figure 2: Risk Difference in procedure success. 
Mortality associated with procedure

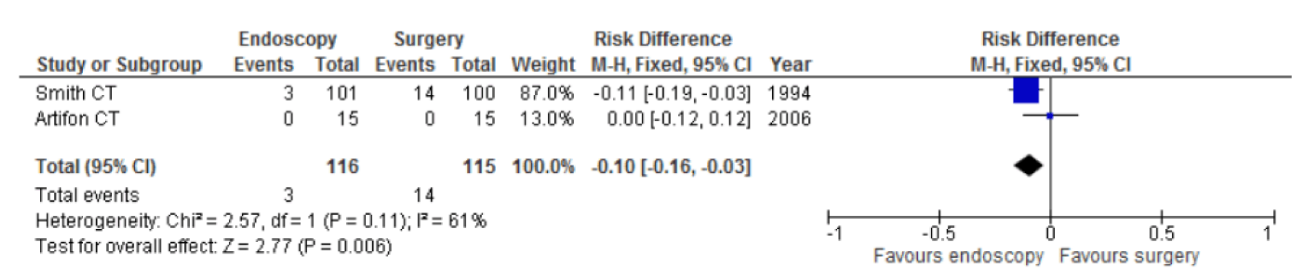

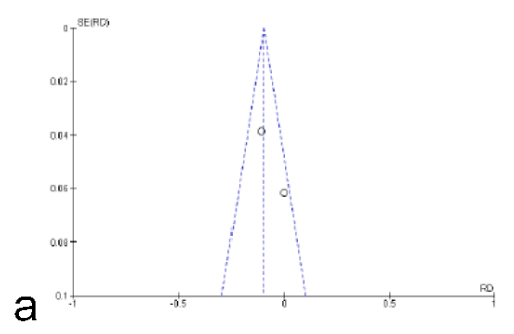

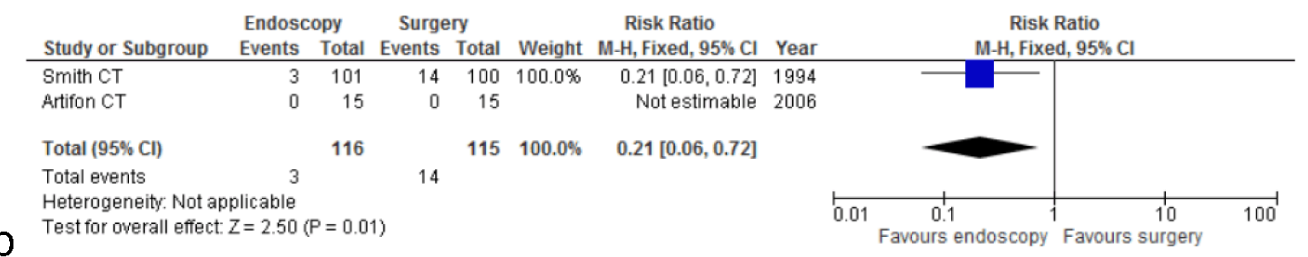

Figure 3: (a) Risk difference in mortality associated with procedure for endoscopy and surgery therapies. (b) Risk ratio in mortality associated with procedure for endoscopy and surgery therapies.

\section{Mortality 30 Days}

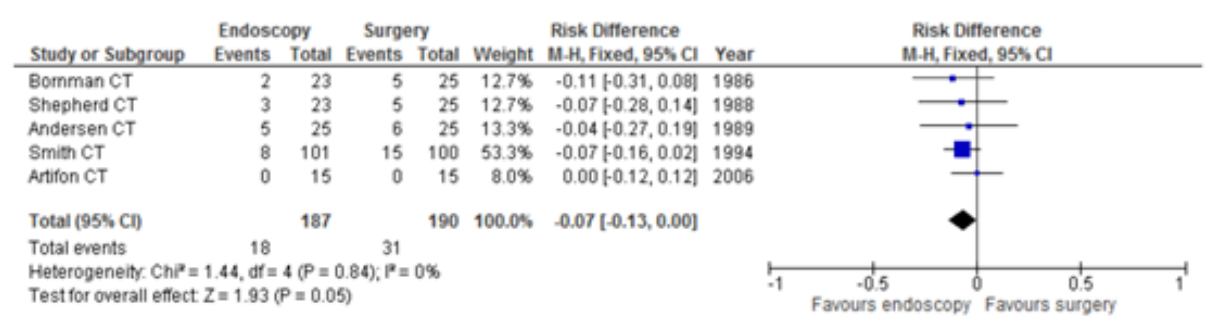

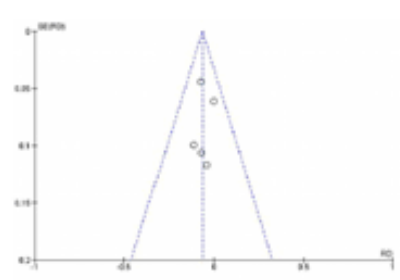

Figure 4: Risk Difference in mortality 30 days. 


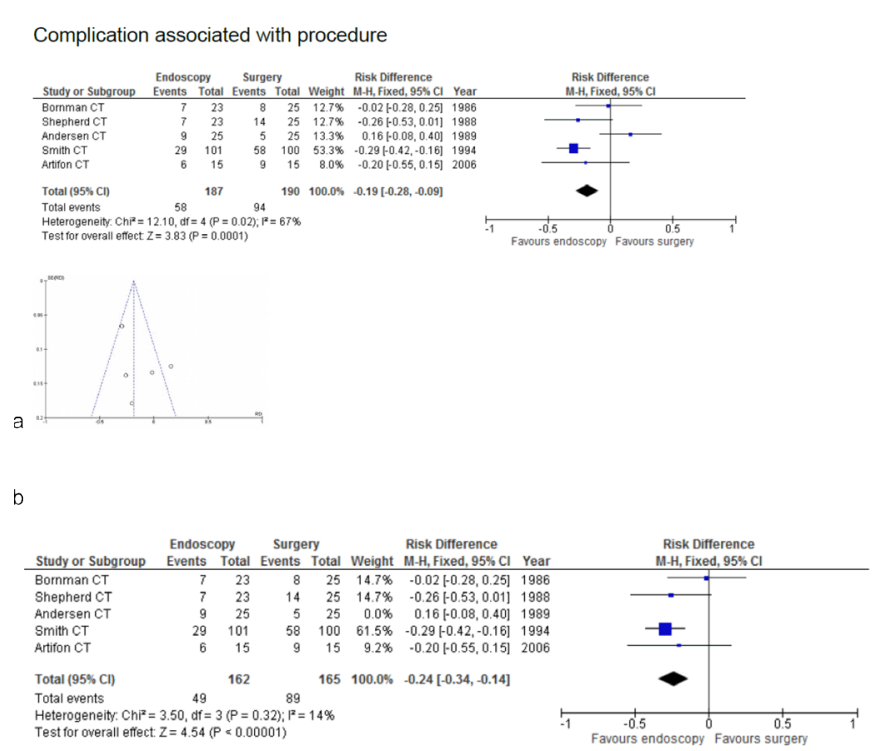

Figure 5: (a) Risk difference in complication associated with procedure for endoscopy and surgery therapies. (b) Risk difference in complication associated with procedure for endoscopy and surgery therapies.

Recurrent-Jaundice
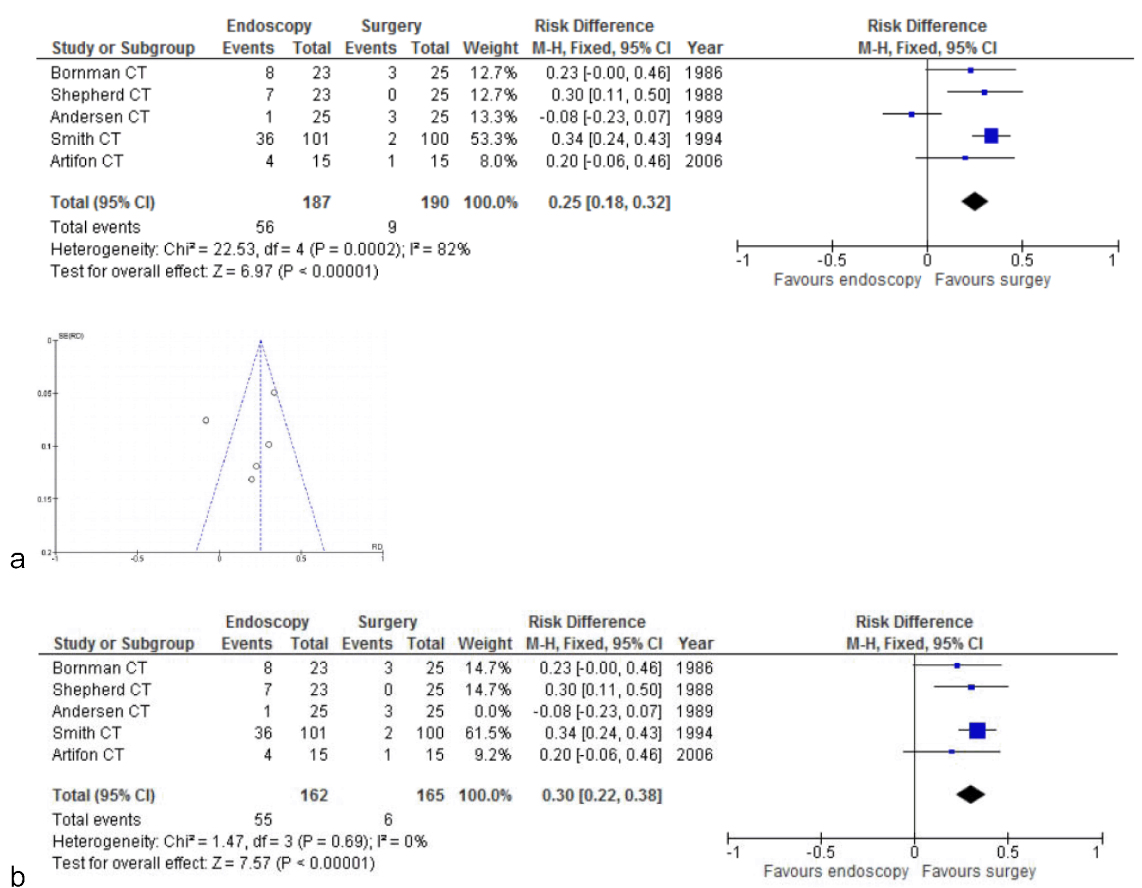

Figure 6: (a) Risk difference in Recurrent-Jaundice. (b) Risk difference in Recurrent-Jaundice for endoscopy and surgery therapies.

reviewers, we opted to withdraw this work from the metaanalysis of Recurrent-Jaundice (Figure 6b).

Recurrent-Jaundice for endoscopy and surgery therapies: four clinical trials reported RecurrentJaundice; the heterogeneity test indicated a X2 of 1.47 and an I2 of $0 \%$, demonstrating homogeneity. The fixedeffects model was adopted, and the RD was 0.30 (95 \% CI: 0.22, 0.38) (Figure 6b). Analysis of the pooled data revealed statistically significant differences for Recurrent-Jaundice and showed better outcomes for surgery therapy.

\section{Risk of Bias Across Studies}

Although the results of success of the procedure were homogeneous between the studies, and no difference was found between the procedures in clinical trials, there is substantial risk of bias because the concept of success is different for each study. Although all are based on a percentage of reduction of bilirubin, the percentages that determined a successful procedure were different.

Mortality at 30 days was homogeneous between the studies, and statistically significant differences were found between the two therapies that favored endoscopy 
therapy. We believe this result is one of the most solid because it was exposed in all studies in absolute numbers and because the concept of death is unlikely subject to interpretation bias.

With regard to complication associated with procedure, Andersen (1999) was identified as a source of heterogeneity for publication bias. Excluding this study, we analyzed four studies demonstrating low heterogeneity and found statistically significant differences (with low probability of bias) in complication associated with procedure that showed better outcomes for endoscopy therapy.

With regard to Recurrent-Jaundice, Andersen (1999) was identified as a source of heterogeneity for publication bias. Excluding this study, we analyzed four studies demonstrating homogeneity and revealed statistically significant differences (with low probability of bias) in Recurrent-Jaundice analysis that showed better outcomes for surgery therapy.

\section{DISCUSSION}

\section{Summary of Evidence}

About $70 \%$ of patients with periampullary tumors have evidence of obstructive jaundice at the time of presentation. Therefore, the main goal of palliative therapy in those patients is to resolve the biliary obstruction. Five randomized controlled trials comparing the outcomes of endoscopic stent placement versus surgical bypass for palliation therapy was analyzed.

No statistically significant differences were found in procedure success between the two therapies. Differences were found between mortality associated with procedure that favored the endoscopy therapy. There was significant risk of bias in this affirmation, and the risk ratio was o.21. Statistically, significant differences (NNT 14) in mortality at 30 days between the two therapies favors endoscopy therapy. This is perhaps the most striking result unidentified in previous reviews. Also, statistically significant differences (NNT 4) in complication associated with procedure between the two therapies favors endoscopy therapy. Finally, statistically significant differences (NNH 3) were found for Recurrent-Jaundice and showed better outcomes for surgery therapy.

\section{LIMITATIONS}

Several limitations of the present study need to be considered. The characteristics of patients were not comparable in some studies. Although the studies were homogeneous in age, some studies had different average ages, which may lead to a significant bias in the results. Several endoscopic therapies including plastic stent and metallic stent (covered or uncovered) were used, and may be bias generator. The type of operation used was also different in all studies and may cause some biases. Finally, publication bias might exist when including published studies because positive results are more likely to be published than negative results.

\section{CONCLUSION}

Endoscopic palliative drainage is associated with a lower rate of complication as well as mortality associated with procedure and mortality within 30 days. Recurrentjaundice analysis demonstrated an overall lower rate in surgical bypass procedures.

\section{$* * * * * * * * *$}

\section{Author Contributions}

Silvia Lucia Alves de Lima - Conception and design, Acquisition of data, Analysis and interpretation of data, Drafting the article, Critical revision of the article, Final approval of the version to be published

Fabio Alberto Castillo Bustamante - Conception and design, Acquisition of data, Analysis and interpretation of data, Drafting the article, Critical revision of the article, Final approval of the version to be published

Eduardo GuimarãesHourneaux de Moura - Conception and design, Acquisition of data, Analysis andinterpretation of data, Drafting the article, Critical revision of the article, Final approval of the version to be published

Wanderley Marques Bernardo - Conception and design, Acquisition of data, Analysis and interpretation of data, Drafting the article, Critical revision of the article, Final approval of the version to be published

Everson Luiz de Almeida Artifon - Analysis and interpretation of data, Drafting the article, Critical revision of the article, Final approval of the version to be published

Dalton Marques Chaves - Analysis and interpretation of data, Drafting the article, Critical revision of the article, Final approval of the version to be published

Tomazo Antonio Prince Franzini - Analysis and interpretation of data, Drafting the article, Critical revision of the article, Final approval of the version to be published

Carlos Kiyoshi Furuya Junior-Analysis andinterpretation of data, Drafting the article, Critical revision of the article, Final approval of the version to be published

\section{Guarantor}

The corresponding author is the guarantor of submission.

\section{Conflict of Interest}

Authors declare no conflict of interest.

\section{Copyright}

(C) 2015 Silvia Lucia Alves de Lima et al. This article is distributed under the terms of Creative Commons Attribution License which permits unrestricted use, 
distribution and reproduction in any medium provided the original author(s) and original publisher are properly credited. Please see the copyright policy on the journal website for more information.

\section{REFERENCES}

1. Bonnel D, André T, Mader B, Lefebvre JF, Bensoussan E, Liguory C. Malignant biliary obstruction, general review and clinical practice. Bull Cancer 2013 May;100(5):443-52.

2. Deviere J, Baize M, Gelin M, et al. Treatment of cancer of the head of the pancreas. Surgery and/or endoscopic prostheses. Acta Gastroenterol Belg 1987 Jan-Feb;50(1):137-46.

3. Ho CS, Warkentin AE. Evidence-based decompression in malignant biliary obstruction. Korean $\mathrm{J}$ Radiol 2012 Jan-Feb;13 Suppl 1:S56-61.

4. Distler M, Kersting S, Rückert F, et al. Palliative treatment of obstructive jaundice in patients with carcinoma of the pancreatic head or distal biliary tree. Endoscopic stent placement vs. hepaticojejunostomy. JOP 2010 Nov 9;11(6):568-74.

5. Smigielski J, Holynski J, Kococik M, et al. Paliative procedures in cholangiocarcinomas--experience of 5 centers. Pol Merkur Lekarski 2009 May;26(155):4169.

6. Edge SB, Byrd DR, Compton CC. AJCC (American Joint Committee on Cancer) Cancer Staging Manual, 7th edition. New York: Springer; 2010.

7. Moss AC, Morris E, Leyden J, MacMathuna P. Malignant distal biliary obstruction: A systematic review and meta-analysis of endoscopic and surgical bypass results. Cancer Treat Rev 2007 Apr;33(2):21321.

8. Artifon EL, Sakai P, Cunha JE, et al. Surgery or endoscopy for palliation of biliary obstruction due to metastatic pancreatic cancer. Am J Gastroenterol 2006 Sep;101(9):2031-7.

9. Tran TC, Vitale GC. Ampullary tumors: endoscopic versus operative management. Surg Innov 2004 Dec;11(4):255-63.

10. Sunpaweravong S, Ovartlarnporn B, Khow-ean U, Soontrapornchai P, Charoonratana V. Endoscopic stenting versus surgical bypass in advanced malignant distal bile duct obstruction: cost-effectiveness analysis. Asian J Surg 2005 Oct;28(4):262-5.

11. House MG, Choti MA. Palliative therapy for pancreatic/biliary cancer. Surg Oncol Clin N Am 2004 Jul;13(3):491-503, ix.

12. Andtbacka RH, Evans DB, Pisters PW. Surgical and endoscopic palliation for pancreatic cancer. Minerva Chir 2004 Apr;59(2):123-36.

13. Maosheng D, Ohtsuka T, Ohuchida J, et al. Surgical bypass versus metallic stent for unresectable pancreatic cancer. J Hepatobiliary Pancreat Surg 2001;8(4):367-73.

14. Ihse I, Hansson L, Hammarström LE, Lindström E. Stent or surgery for malignant low bile duct obstruction? HPB Surg 1997;10(3):179-81.
15. Mitty R, Cave DR. Randomized trial of endoscopic stenting versus surgical bypass in malignant low bile duct obstruction. Gastrointest Endosc 1995 Sep;42(3):281-2.

16. Arvanitakis M, Devière J. Endoscopic retrograde cholangiopancreatography. Endoscopy 2004 Oct;36(10):855-9.

17. Baumel H, Huguier M, Fabre JM. Palliative treatment of cancers of the head of the pancreas. Surgery versus endoscopy. Ann Chir 1995;49(2):110-5; discussion 116-20.

18. York, University of. 2014. http://www.crd. york.ac.uk/PROSPERO/display_record.asp? ID=CRD42014013170 (accessed o8 11, 2014).

19. Jadad AR, Moore RA, Carroll D, et al. Assessing the quality of reports of randomized clinical trials: is blinding necessary? Control Clin Trials 1996 Feb;17(1):1-12.

20. Wells GA, Shea B, O'Connell D, et al. The NewcastleOttawa Scale (NOS) for assessing the quality of nonrandomised studies in meta-analyses 2015. http:// www.ohri.ca/programs/clinical_epidemiology/ oxford.asp (accessed 08 03, 2014).

21. Scotland, Healtcare improvment. 2015. http://www. sign.ac.uk/guidelines/index.html (accessed o8 4, 2014).

22. Group, OCEBM Levels of Evidence Working. "The Oxford Levels of Evidence 2?. Oxford Centre for Evidence-Based Medicine. 08 03, 2014. http://www. cebm.net/index.aspx?o=5653.

23. Department, Cochrane Informatics and Knowledge Manegement. 2014. http://tech.cochrane.org/ revman/download (accessed 10 5, 2014).

24. Distler M, Kersting S, Rückert F, et al. Palliative treatment of obstructive jaundice in patients with carcinoma of the pancreatic head or distal biliary tree. Endoscopic stent placement vs. hepaticojejunostomy. JOP 2010 Nov 9;11(6):568-74.

25. Maosheng D, Ohtsuka T, Ohuchida J, et al. Surgical bypass versus metallic stent for unresectable pancreatic cancer. J Hepatobiliary Pancreat Surg 2001;8(4):367-73.

26. Smith AC, Dowsett JF, Russell RC, Hatfield AR, Cotton PB. Randomised trial of endoscopic stenting versus surgical bypass in malignant low bileduct obstruction. Lancet 1994 Dec 17;344(8938):1655-60.

27. Andersen JR, Sørensen SM, Kruse A, Rokkjaer M, Matzen P. Randomised trial of endoscopic endoprosthesis versus operative bypass in malignant obstructive jaundice. Gut 1989 Aug;30(8):1132-5.

28. Shepherd HA, Royle G, Ross AP, Diba A, Arthur M, Colin-Jones D. Colin-Jones D. Endoscopic biliary endoprosthesis in the palliation of malignant obstruction of the distal common bile duct: a randomized trial. Br J Surg 1988 Dec;75(12):1166-8.

29. Bornman PC, Harries-Jones EP, Tobias R, Van Stiegmann G, Terblanche J. Prospective controlled trial of transhepatic biliary endoprosthesis versus bypass surgery for incurable carcinoma of head of pancreas. Lancet 1986 Jan 11;1(8472):69-71. 


\section{ABOUT THE AUTHORS}

Article citation: Alves de Lima SL, Bustamante FAC, Hourneaux de Moura EG, Bernardo WM, Artifon ELA, Chaves DM, Franzini TAP, Junior CKF. Endoscopic palliative treatment versus surgical bypass in malignant low bile duct obstruction: A systematic review and meta-analysi. Int J Hepatobiliary Pancreat Dis 2015;5:35-46.

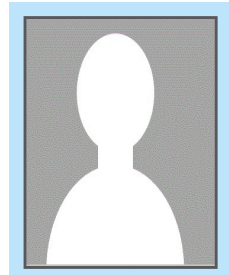

Silvia Lucia Alves de Lima, MD Gastrointestinal Endoscopy Unit, Hospital das Clinicas, University of Sao Paulo Medical School. São Paulo, São Paulo, Brazil. She earned the undergraduate degree MD from BotucatuMedical School, São Paulo, São Paulo, Brazil. and postgraduate degree in Gastrointestinal Surgery from Hospital das Clinicas, University of Sao Paulo Medical School. São Paulo, São Paulo, Brazil. Fellow, Gastrointestinal Endoscopy Unit, Hospital das Clinicas, University of Sao Paulo Medical School. São Paulo, São Paulo, Brazil. His research interests include Gastrointestinal Endoscopy Gastrointestinal Surgery Diagnosis and Treatment of pancreatic and biliary pathologies.

E-mail: silvia_lima@yahoo.com.br

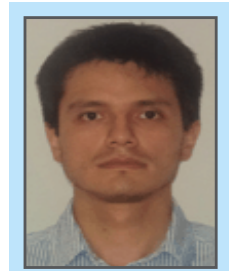

Fabio Alberto Castillo Bustamante, MD Gastrointestinal Endoscopy Unit, Hospital das Clinicas, University of Sao Paulo Medical School. São Paulo, São Paulo, Brazil. He earned the undergraduate degree MD from Universidad Nacional de Colombia, Bogota, Colombia and postgraduate degree inGeneral Surgeon from General Surgery Department, Universidad El Bosque, Bogotá, Colombia. Fellow, Gastrointestinal Endoscopy Unit, Hospital das Clinicas, University of Sao Paulo Medical School. São Paulo, São Paulo, Brazil. His research interests include Gastrointestinal Endoscopy Gastrointestinal Surgery Treatment of Early Neoplasia Digestive System Diagnosis and Treatment of pancreatic and biliary pathologies. He intends to pursuePhD'sin future.

E-mail: facastillobu@gmail.com

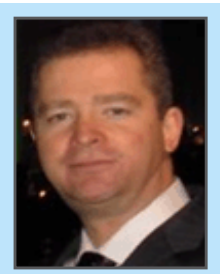

Eduardo Guimarães Hourneaux de Moura is Graduated in Medicine, Faculty of Medical and Health Sciences from the Catholic University of São Paulo (1984), Master in Medicine by the Brazilian Institute of Studies and Gastroenterology Research - IBEPEGE (1985), Doctorate in Medicine from the University of Medicine São Paulo - USP (2000) and Full Professor at the Faculty of Medicine, University of São Paulo (2012). He is currently Director of the Gastrointestinal Endoscopy Service and Broncoesofagoscopia the Hospital das Clínicas, Advisor of the Graduate Program of Science in USP of Gastroenterology, Medical Associate Professor in the Department of Digestive Surgery, Department apparatus. of USP Gastroenterology, Supervisor of the Medical Residency Program in the Endoscopy Coreme-USP.

E-mail: eduardoghdemoura@gmail.com

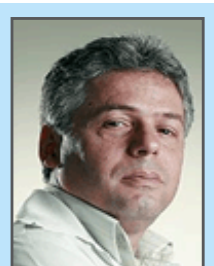

Wanderley Marques Bernardo is Graduated in Medicine, Faculty of Medical Sciences of Santos (1984) and a PhD in thoracic Surgery, Faculty of Medicine, University of São Paulo (2003). He is currently coordinator of the Knowledge Center, Faculty of Medicine, University of Sao Paulo, Coordinator of the Program Guidelines of the Brazilian Medical Association and the Federal Council of Medicine; Professor Doctor University Center Lusiada, Medical School. Has experience in the area of medicine, with an emphasis on evidence-based medicine, acting on the following subjects: evidencebased medicine, medical guidelines, systematic reviews, clinical decision, practice guidelines and Technology Assessment.

E-mail: wmbernardo@usp.br 


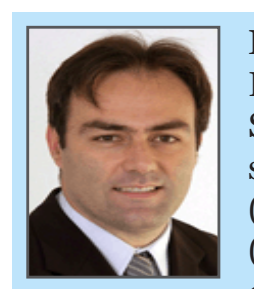

Everson Luiz de Almeida Artifon is Graduated in Medicine from the Federal University of Paraná (1994), specialization in Title Specialist In Chirurgie Dig by the Brazilian College of Digestive Surgery (1997), specialization Specialist in General Surgery by the Brazilian College of Surgeons (1998) specialization in the Title In Digestive Endoscopy by the Brazilian Society of Digestive Endoscopy (2001), Master of Medicine (Digestive System Surgery), University of São Paulo (2001), PhD in Medicine (Surgery of the Digestive System), University of São Paulo (2004), post-doctorate from the Faculty of Medicine, USP (2005), residence-doctors from the University of São Paulo (2001) and residencedoctors from the State University of Campinas (1998). He is currently Head of the Hospital Ana Costa Service, Chief of Endoscopy Service of the Hospital Ana Costa, Hospital Medical AlemãoOswaldo Cruz, Assistant Physician, Hospital of the School of USP, Physician Hospital Assistant of the School of Medicine Clinics University of São Paulo.

E-mail: eartifon@hotmail.com

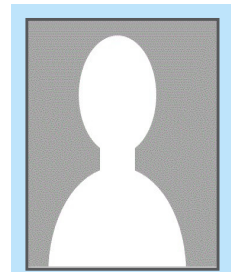

Dalton Marques Chaves is Graduated in Medicine from the Federal University of Uberlândia (1986), specializing in Endoscopy, Digestive System by the Hospital of the USP (1991), master's degree from the University of São Paulo (1995), Doctorate of Science (Human Physiology) from the University of St. Paul (2001), post-doctorate from the California Pacific Medical Center (2004) and residence-doctors from the Federal University of Uberlândia (1989). He is currently Medical Endoscopy Service of the Hospital of the USP, Member of the Brazilian Society of Digestive Endoscopy, Member of the Regional Council of Medicine of São Paulo, Medical EndoscopistFleury Group, Member of The American Society for Gastrointestinal Endoscopy and regular reviewer of Gastrointestinal Endoscopy.

E-mail: dalton.chaves@grupofleury.com.br

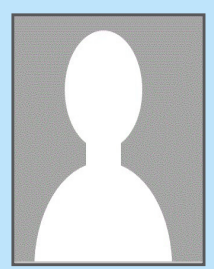

Tomazo Antonio Prince Franzini is Graduated in Medicine from the University of Mogi das Cruzes, Medical residency in general surgery by FMABC, Specialization in Gastrointestinal Endoscopy at HCFMUSP, Specialist in Endoscopy by SOBED, international Member of the ASGE (American Society of Gastrointestinal Endoscopy). PhD in Sciences in Gastroenterology at the Faculty of Medicine, University of São Paulo. He is currently assistant physician endoscopist HCFMUSP University of São Paulo, endoscopist doctor Unimed Limeira Hospital and medical endoscopy, Hospital São LuizMorumbi / Jabalpur - SP.

E-mail: tomazof@uol.com.br

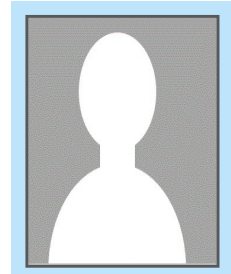

Carlos Kiyoshi Furuya Junior is MD Gastrointestinal Endoscopy Unit, Hospital das Clinicas, University of Sao Paulo Medical School. São Paulo, São Paulo.

Extensãouniversitáriaem ENDOSCOPIA. Universidade de São Paulo, USP, Brasil.

E-mail: carloskfjr@yahoo.com.br

Access full text article on other devices

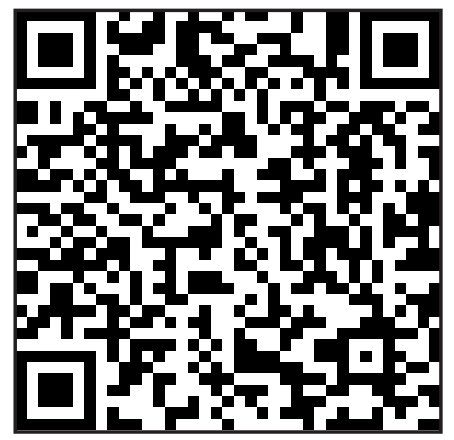

Access PDF of article on other devices

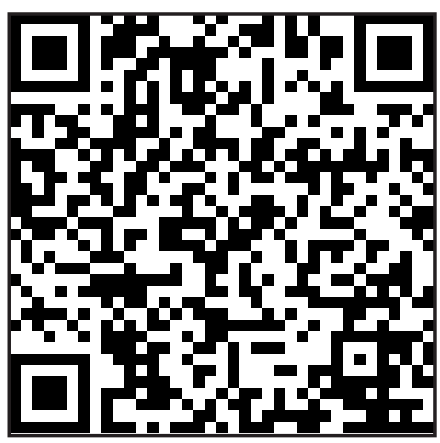

